УДК 81'42

ББК 81

DOI: https://doi.org/10.17308/lic.2021.2/3426

\title{
СЛАВЯНСКИЕ ЯЗЫКИ В РАКУРСЕ ТИПОЛОГИИ
}

(Рец. на кн.: Меркулова И. А. Лексико-семантические ядра славянских языков в сопоставительном аспекте. Воронеж, 2021. 255 с.)

\author{
С. М. Белякова \\ Тюменский государственный университет
}

\section{SLAVIC LANGUAGES FROM THE TYPOLOGICAL PERSPECTIVE (Review of Merkulova I. A. Leksiko-semanticheskie jadra slavyanskikh jazykov $v$ sopostavitelnom aspekte [Lexico-semantic cores of the Slavic languages: a comparative analysis]. Voronezh, 2021. 255 p.)}

\author{
S. M. Belyakova \\ Tyumen State University
}

Монография И. А. Меркуловой посвящена выявлению и лингвистическому исследованию феномена лексико-семантического ядра современных славянских языков, что напрямую связано с проблемой системного изучения лексики. Поскольку эта проблема остается одной из актуальнейших в современном языкознании, такая попытка априори заслуживает внимания и высокой оценки.

Своей работой автор утверждает и практически реализует новое направление отечественной лингвистики - лексическую нуклеологию, ставящую своей целью целостное и системное описание лексики, что и выполнено на нетривиальных, но весьма убедительных основаниях. Перед нами значительный труд, посвященный исследованию лексических ядер практически всех живых славянских языков. Методология квантитативной лексикологии (ее можно считать предтечей нуклеологии), типологических исследований, а также методика описания и сопоставления были разработаны и практически осуществлены в трудах А. А. Кретова, В. Т. Титова, О. В. Богдановой, Т. А. Казаковой, Д. С. Воевудского, О. М. Воевудской, Е. В. Долбиловой и других ученых, представляющих Воронежскую лингвистическую школу. Среди таких трудов значительное место занимает книга «Единство Европы по данным лексики» [1], одним из авторов которой является И. А. Меркулова.
Новая монография этого исследователя развивает обозначенное направление и вносит существенный вклад в дальнейшую разработку сопоставительной и типологической лексикологии.

Поставленная проблема решается на весьма специфическом материале славянских языков. Каждому, кто соприкасался с каким-либо из этих языков, знакомо завораживающее чувство сходства, близкого родства и в то же время - открывающейся самобытности другой лингвокультуры, архаики и новаций иной части Славии. При наличии значительного количества лингвистических работ, посвященных славянским языкам, непрекращающемуся научному интересу к ним в нашей стране и за рубежом мы вынуждены констатировать наличие «белых пятен» в этой отрасли гуманитарного знания, связанных в том числе и с давно решенной, казалось бы, проблемой классификации. Однако если генеалогическую классификацию этих языков со времен А. Х. Востокова можно считать общепринятой, то их типологическая группировка вызывает много вопросов. Автор монографии предлагает решение этой проблемы путем использования методологии и методики лексической нуклеологии.

Разрабатываемая названной научной школой гипотеза базируется на представлении о существовании лексического ядра языка, выделение которого осу-

(C) Белякова С. М., 2021 
ществляется по нескольким параметрам: функциональному (оценивается по длине слова), синтагматическому (оценивается по возможности образовывать фразеологизмы), эпидигматическому (оценивается по количеству значений), парадигматическому (оценивается по длине синонимического ряда). С учетом данных параметров И. А. Меркуловой были выделены частные и затем - «большие» параметрические ядра всех 14 языков. Полученные ядра далее подверглись сопоставлению и генерализации, результат чего позволил представить общую картину лексической макротипологии славянского континуума. Исключительно велик объем использованного лингвистического материала: список словарей, которые и подверглись обработке, составляет 59 позиций, они изданы в разных странах и отражают различные лексикографические традиции.

Поставленные задачи обусловили структуру монографии. Первая глава посвящена общим принципам сопоставительного описания лексики славянских языков. В ней представлен прежде всего обзор широкого круга работ, затрагивающих указанные вопросы, начиная с трудов представителей сравнительноисторического направления и заканчивая исследованиями современных славистов и компаративистов. Рассматриваются, в частности, проблемы системности лексики, сопоставительной лексикологии, поиски особого объекта сравнения, используемых для этой цели методов и т. д. Этот обзор предваряет экспликацию концентрической модели лексико-семантической системы языка и характеристику предлагаемого научного направления - лексической нуклеологии.

Описание и комментирование указанных параметров лексико-семантических ядер славянских языков последовательно производится в главах 2-5 рецензируемой монографии.

Анализ параметров проводится автором монографии самым тщательным и квалифицированным образом и в целом выглядит вполне убедительно. Тем не менее в некоторых случаях возникают определенные сомнения и вопросы. Один из них касается функционального параметра, т. е. распределения славянских языков по длине слова (при этом указывается, что такой метод является не прямым, а косвенным показателем активности), который позволяет автору сделать вывод о делении этих языков на северные (длина более 8 букв) и южные (длина немногим более 7 букв). Как нам представляется, пороговое значение здесь не кажется релевантным. Не следует забывать и о специфике фонетического строя отдельных языков. Хорошо известно, что в чешском и сербском языках существуют слоговые плавные, что дает возможность «экономить на гласных», сокращая тем самым длину слова. При этом подкрепленный обширным материалом вывод о «постепенном укорачива- нии» наиболее употребительных корней кажется нам весьма интересным.

Наконец, в последней, шестой, главе полученные ранее данные сводятся воедино. Каждый язык представлен, таким образом, четырьмя ядрами. При таком сопоставлении выявляются нуклеарно-семантические универсалии, уникалии (присущие лишь одному языку) и эксклюземы (объединяющие какую-либо пару языков).

Постепенно перед нами возникает сложная, многообразная лингвистическая картина славянского мира с ее переплетениями западно-, южно- и восточнославянских характеристик, общими и частными закономерностями, взаимовлияниями, притяжениями и отталкиваниями, различными степенями типологической близости. Многие из полученных выводов заслуживают особого внимания. Так, безусловно, важными представляются данные о нуклеарных доминантах, позволяющих соотнести их с особенностями менталитета носителей того или иного языка. В частности, выделяются «языки движения» (украинский, польский и др.), «языки дела» (словенский, чешский), «языки человека» (словацкий, хорватский), «языки обладания-наделения» (русский, македонский) и некоторые другие. Существенным можно считать и вывод о ключевых для славянской лингвокультуры словах (понятиях), связанных с движением, мерой, порядком, телесностью человека и феноменом времени, что в какой-то степени подтверждает выводы, полученные исследователями ранее. В результате построения нуклеарной лексико-семантической карты становится очевидным центральное положение в ней русского языка, что, безусловно, объясняется тем влиянием, которое русская лингвокультура в разные периоды своего существования оказывала на инославянские языки и культуры. На дальней периферии оказываются лехитские языки: польский и кашубский.

Некоторые из полученных данных не представляются столь логичными и очевидными и нуждаются, на наш взгляд, в комментариях. К ним принадлежат, например, обобщающий вывод по сопоставлению синтагматических ядер. Из него следует, что чешский язык является центром распределения славянских языков по данному параметру. «Он показывает наиболее прочные связи с языками всех генетических групп» (с. 124). При этом другие параметры отнюдь не демонстрируют подобную «центральность» данного языка. Хотелось бы увидеть какое-либо объяснение этого феномена.

В результате исследования автор приходит к центральному и, безусловно, убедительному выводу, что «типологическая классификация родственных языков не воспроизводит их генетическую классификацию» (c. 216), и это подтверждает выдвинутую гипотезу. 
Из 14 языков только 8 совпадают генетически и типологически (вычислены также коэффициенты близости), что дает возможность говорить об уникальности типологических характеристик многих славянских языков и расставлять новые акценты при их изучении.

Некоторые сомнения вызывает категоричность вывода о первоначальном членении единого славянского континуума на северные и южные языки (см. с. 220, подобное утверждение приводилось автором и ранее). Традиционная точка зрения, восходящая к взглядам А. А. Шахматова и подтвержденная работами С. Б. Бернштейна, Ф. П. Филина, Х. Бирнбаума, А. Е. Супруна, С. С. Скорвида и других исследователей, о первоначальном членении славянских языков (диалектов) на западные и восточные долгое время была в нашей науке общепринятой. Она базируется на известных фонетических фактах и отражена, в частности, в академическом издании «Языки мира: Славянские языки» [2] и других трудах. Мы, разумеется, не отказываем автору в праве на свою точку зрения, тем более подтвержденную убедительными данными из области лексики. Хотелось бы только указать на противоречие фонетических и лексических фактов и увидеть объяснение этому. На наш взгляд, это свидетельствует о сложности и многоэтапности формирования славянского лингвистического ландшафта.

Подчеркнем, что анализ ядерной лексики славянских языков наглядно демонстрируется таблицами, графиками, рисунками и схемами. Укажем, что количество только таблиц в структуре монографии достигает 101 единицы. Безусловно, такое представление материала обладает высокой информативностью. Необходимо также отметить и прекрасный стиль изложения столь сложного материала, корректность формулировок и обобщений.

Тюменский государственный университет

Белякова С. М., профессор кафедры русского языка и общего языкознания

E-mail: smbelyakova@gmail.com

Поступила в редакцию 1 марта 2021 г.

Принята к публикации 22 марта 20212.

\section{Для цитирования:}

Белякова С. М. Славянские языки в ракурсе типологии (Рец. на кн.: Меркулова И. А. Лексико-семантические ядра славянских языков в сопоставительном аспекте. Воронеж, 2021. 255 с.) // Вестник Воронежского государственного университета. Серия: Лингвистика и межкультурная коммуникация. 2021. № 2. С. 158-160. DOI: https://doi.org/10.17308/lic.2021.2/3426
В заключение мы хотим еще раз подчеркнуть теоретическую основательность, капитальность этой работы, огромный объем языковых фактов, обработанных с применением новейших информационных технологий. Несомненно, монография И. А. Меркуловой обогащает и теорию языка, и сопоставительную лексикологию, и типологическую лингвистику новыми идеями и языковыми фактами, перспективной методологией. Многоаспектное исследование славянской лексики в рамках заявленного подхода показало его плодотворность и перспективность, обоснованность и доказательность основных положений и выводов. Некоторые наши частные замечания и вопросы лишь подтверждают научную значимость и актуальность труда, вызвавшего интерес у рецензента.

Солидная база данных по лексике славянских языков, полученная в результате обработки большого количества словарей, может быть использована для дальнейших исследований сходной тематики. Мы уверены, что книга будет активно использоваться в научной работе, в том числе и при составлении словарей различных типов, а также в практике преподавания русским и иностранным студентам теоретических лингвистических дисциплин.

\section{ЛИТЕРАТУРА}

1. Кретов А. А. [и др.]. Единство Европы по данным лексики. Воронеж, 2016. 412 с.

2. Славянские языки / под ред. А. Г. Широковой, В. П. Гудкова. М. : Изд-во Моск. ун-та, 1977. 375 с.

\section{REFERENCES}

1. Kretov A. A. and others. Edinstvo Evropy po dannym leksiki. Voronezh, 2016. $412 \mathrm{p}$.

2. Slavyanskie yazyki. Pod red. A. G. SHirokovoj, V. P. Gudkova. M.: Izd-vo Mosk. un-ta, 1977. 375 p.

Tyumen State University

Belyakova S. M., Professor of the Russian Language and General Linguistics Department

E-mail:smbelyakova@gmail.com

Received: 1 March 2021

Accepted: 22 March 2021

\section{For citation:}

Belyakova $S$. M. Slavic languages from the typological perspective (Review of Merkulova I. A. Leksikosemanticheskie jadra slavyanskikh jazykov v sopostavitelnom aspekte [Lexico-semantic cores of the Slavic languages: a comparative analysis]. Voronezh, 2021.255 p.). Proceedings of Voronezh State University. Series: Linguistics and Intercultural Communication. 2021. No. 2. Pp. 158-160. DOI: https://doi.org/10.17308/lic.2021.2/3426 